\title{
Modern contraceptive use among female refugee adolescents in northern Uganda: prevalence and associated factors
}

\author{
Ritah Bakesiima ${ }^{1,2^{*}}$ (D) Amanda Cleeve ${ }^{2}$, Elin Larsson ${ }^{2,3}$, James K. Tumwine ${ }^{4}$, Grace Ndeezi ${ }^{4}$, \\ Kristina Gemzell Danielsson ${ }^{2}$, Rose Chalo Nabirye ${ }^{5}$ and Jolly Beyeza Kashesya ${ }^{1}$
}

\begin{abstract}
Background: Adolescent pregnancies are persistently high among refugees. The pregnancies have been attributed to low contraceptive use in this population. The aim of this study was to determine the prevalence and factors associated with modern contraceptive use among female refugee adolescents in northern Uganda.

Methods: This was a cross sectional study using both descriptive and analytical techniques. The study was carried out in Palabek refugee settlement in Northern Uganda from May to July 2019. A total of 839 refugee adolescents who were sexually active or in-union were consecutively enrolled. Interviewer administered questionnaires were used for data collection.

Results: Modern contraceptive prevalence was $8.7 \%$ ( $95 \% \mathrm{Cl}: 7.0$ to 10.8). The injectable was the most commonly used modern contraceptive method [42.5\% (95\% Cl: 31.5 to 54.3)], and most of the participants had used the contraceptives for 6 months or less (59.7\%). Reasons for not using modern contraceptives included fear of side effects (39.3\%), partner prohibition (16.4\%), and the desire to become pregnant (7.0\%). Participants who were married ( $\mathrm{OR}=0.11,95 \% \mathrm{Cl}: 0.04$ to $0.35, p<0.001)$, cohabiting $(\mathrm{OR}=0.43,95 \% \mathrm{Cl}: 0.20$ to $0.93, p=0.032)$ or having an older partner ( $\mathrm{OR}=0.93,95 \% \mathrm{Cl}: 0.86$ to $0.99, p=0.046$ ) were less likely to use modern contraceptives.

Conclusion: Modern contraceptive use among female refugee adolescents was very low, and few reported a desire to become pregnant, leaving them vulnerable to unplanned pregnancies. Least likely to use modern contraceptives were participants who were married/cohabiting and those having older partners implying a gender power imbalance in fertility decision making. There is an urgent need for innovations to address the gender and power imbalances within relationships, which could shape fertility decision-making and increase modern contraceptive use among refugee adolescents.
\end{abstract}

Keywords: Modern contraceptives, Contraception, Refugees, Adolescents, Teenage pregnancies

\footnotetext{
* Correspondence: esmie.ritah@gmail.com

'Department of Obstetrics and Gynaecology, School of Medicine, College of

Health Sciences, Makerere University, Kampala, Uganda

${ }^{2}$ Department of Women's and Children's Health, Division of Obstetrics and

Gynaecology, Karolinska Institutet, and Karolinska University Hospital,

Stockholm, Sweden

Full list of author information is available at the end of the article
}

C C The Author(s). 2020 Open Access This article is licensed under a Creative Commons Attribution 4.0 International License, which permits use, sharing, adaptation, distribution and reproduction in any medium or format, as long as you give appropriate credit to the original author(s) and the source, provide a link to the Creative Commons licence, and indicate if changes were made. The images or other third party material in this article are included in the article's Creative Commons licence, unless indicated otherwise in a credit line to the material. If material is not included in the article's Creative Commons licence and your intended use is not permitted by statutory regulation or exceeds the permitted use, you will need to obtain permission directly from the copyright holder. To view a copy of this licence, visit http://creativecommons.org/licenses/by/4.0/ The Creative Commons Public Domain Dedication waiver (http://creativecommons.org/publicdomain/zero/1.0/) applies to the data made available in this article, unless otherwise stated in a credit line to the data. 


\section{Plain English summary}

Adolescent pregnancies are persistently high globally, with higher rates reported among refugees and migrants. These expose the affected girls to the complications associated with teenage pregnancy and child birth, which are the leading cause of death among girls aged 15 to 19 years globally. The high rates of adolescent pregnancies have been attributed to low contraceptive use amongst the adolescents. However, there is scarce information on contraceptive use among refugee adolescents. A total of 839 female refugee adolescents were enrolled in order to determine the prevalence and factors associated with modern contraceptive use in this population in Palabek refugee settlement, Northern Uganda. It was found that modern contraceptives were used by less than a tenth of the participants, and yet the majority did not want to get pregnant. Since the participants were sexually active, their low use of modern contraceptives meant that they were vulnerable to unwanted or unplanned pregnancy and its associated complications. Some of the reasons for not using modern contraceptives included fear of side effects and partner prohibition. Adolescents who were married/cohabiting, and those who had older partner were less likely to use modern contraceptives. This could be explained by gender power imbalances which leave the adolescents with lower negotiating power compared with adult women, especially surrounding matters that concern their sexual and reproductive health. There is an urgent need for measures to improve adolescents' access to high-quality sexual and reproductive healthcare in refugee settings, with more emphasis put on empowering them to make decisions about their own health including initiating a contraceptive method. Interventions should also aim at addressing fear of side effects and increasing knowledge on modern contraceptives.

\section{Introduction}

Refugees are rapidly increasing worldwide with the number reaching 25.9 million [1]. Uganda is the third largest refugee hosting nation in the world, and the largest in Africa with over 1.3 million refugees from South Sudan, the Democratic Republic of Congo, and Burundi [2]. Over $61 \%$ of these refugees are below 18 years [3].

Refugees are a vulnerable group because of the conflicts, insecurity, and the violence and poverty they often face. Globally, women and children constitute over $80 \%$ of refugee populations [4]. Female refugee adolescents are especially vulnerable due to high risk of sexual violence, exploitation and abuse, and early or forced marriage [4, 5]. Adolescent pregnancies are reported to be higher among refugees or displaced persons than the non-displaced persons at 30 and 19\% respectively [6].

Adolescent pregnancy can be life threatening because of the complications associated with pregnancy and child birth in this age group. Such complications include obstetric fistula, pregnancy induced hypertension, haemorrhagic syndrome, premature rupture of membranes and unsafe abortions among others [7-10]. These complications are the leading cause of death among girls aged 15 to 19 years globally [11].

In 2006, Uganda allowed contraceptive use among sexually active adolescents in order to curb teenage pregnancy rates and associated complications [12, 13]. However, many adolescents are still getting pregnant due to low contraceptive use $[14,15]$. In Uganda, modern contraceptive use among married and unmarried sexually active female adolescents is $25.1 \%$ [16]. This persistently low use and high teenage pregnancy rate in Uganda has been attributed to a number of reasons such as unpredictable and irregular sexual activity, limited access to contraception, inadequate knowledge on contraceptives and fear of side effects $[17,18]$.

When it comes to refugee settings in Uganda, little is known about adolescents' contraceptive use, and sexual and reproductive practices. The aim of this study was therefore to determine the prevalence and factors associated with modern contraceptive use among female refugee adolescents in Northern Uganda. This information is crucial for improving sexual and reproductive health outcomes among refugee adolescents.

\section{Materials and methods}

\section{Study design and setting}

This was a cross sectional study carried out in Palabek refugee settlement from May to July, 2019. Palabek refugee settlement is located in the northern region of Uganda in Lamwo district and has served as a refugee settlement to over 38,000 refugees from South Sudan, $86 \%$ of whom are women and children [4, 19]. The settlement is arranged in zones, which are further divided into blocks. Every block has a community meeting place where members usually meet when summoned by their leaders for any communication.

Palabek refugee settlement has four health centres all of which provide contraceptive services freely to the refugees and to the host community. The contraceptive services provided by the health centres include counselling, giving out of oral contraceptives and condoms, insertion and removal of intra-uterine devices (IUDs) and implants, and giving of injectable contraceptives. Both adolescents and adults receive similar care regarding counselling, privacy and provision of contraceptives. These services are available most of the time, with stock-outs occurring infrequently.

\section{Participants}

Female refugee adolescents were consecutively enrolled into this study. Block leaders asked female refugees to converge in their community meeting places within the 
block. In the meeting place, adolescents were informed about the study, and those who were willing to participate were screened for eligibility. The inclusion criteria were female refugees aged 10 to 19 years, who were in any form of union or unmarried but reported having had sex in the past 3 months, were settled with in Palabek refugee settlement from May to July 2019, and consented to participate in the study. Adolescents were excluded if they were physically or mentally unable to adhere to study procedures like consenting and responding to the interview questions. All adolescents who were informed about the study and were eligible consented to participate in the study.

\section{Sample size calculation}

The sample size was calculated using the Kish Leslie formula [20] for the prevalence objective, in which we assumed an expected prevalence of $50 \%$, meant to give us the largest sample size, and an absolute error or precision of 0.05 . We also factored in non-response of $10 \%$. This gave a sample size of 424 .

To determine the factors associated with modern contraceptive use, the sample size formula for comparing means in two proportions by Hulley [21] was used. We assumed an error of 0.05 , power of $80 \%$, that the proportion of adolescents who are currently married and are using modern contraceptives is $20.7 \%$ [16], while the proportion of unmarried sexually active adolescents using modern contraceptives is $40.3 \%$ [16]. We also used the proportion of adolescents who are currently married in Uganda as 5.6\% [16]. This gave a sample size of 839 . Since this sample size was larger than that obtained from the Kish Leslie formula, it was used as the overall sample size for the study.

\section{Data collection}

Data was collected using a pretested interviewer administered questionnaire. The interviewers were two male and two female research assistants working as village health team members (It is important to note that the gender of the interviewers did not have any significant effect on the responses of the participants according to our post hoc analysis). The interviewers were trained in medical research ethics and given guidance on how to administer the questionnaires. Information obtained with the use of the questionnaire included social demographics, sexual and reproductive history, spousal information and knowledge and use of modern contraceptives. The interviews took place at the community meeting place, in a private space away from other participants where conversations could not be over heard. This was done immediately after informing them about the study, and obtaining their consent to participate. The primary outcome variable was modern contraceptive use while the secondary outcome variables were: types of modern contraceptives used and duration of use of modern contraceptives.

\section{Statistical analysis}

Data was analysed using STATA version 14.0 (StataCorp. 2014. Stata Statistical Software: Release 14). All continuous variables were summarised as means and standard deviations if they were normally distributed, and as medians and ranges if skewed. Categorical variables were summarised as percentages and proportions. Modern contraceptive use was analysed as a categorical variable, with use of modern contraceptives coded as " 1 " and nonuse as "0". Prevalence of use was calculated as the percentage of female refugee adolescents currently using or had used within the past 3 months any modern contraceptives over the total number of participants in the study.

Factors associated with modern contraceptive use were assessed using the logistic regression model. Bivariate analysis was done by fitting a model for all the independent variables with the outcome. All variables that were plausible considering prior knowledge and those gave a $p$-value $\leq 0.2$ at the bivariate analysis were considered for multivariate analysis. At the multivariate analysis, variables were considered statistically significant if they had a $p$-value less than 0.05 . Two-way product terms were formed for the significant variables and were used to assess for interaction using the chunk test. Where necessary, confounding was assessed for and a variable was considered to be a confounder if it caused a greater than or equal to $10 \%$ change in the odds ratio of modern contraceptive use. Odds ratios were presented along with their $95 \%$ confidence intervals, and statistical significance reported at $p<0.05$.

\section{Results}

Background characteristics of the study participants

A total of 839 female adolescents were consecutively enrolled into the study. The age range was 15 to 19 years, and the mean age was 18.3 years $(\mathrm{SD}=0.83)$. As shown in Table 1, seven hundred and twenty-seven (86.7\%) of the participants were adolescents aged 18 years and above and 544 (64.8\%) were either married or cohabiting. Considering the sexual and reproductive history, 169 participants $(20.1 \%)$ had their first sexual intercourse below 16 years, 591 (70.4\%) had ever been pregnant, $432(73.1 \%)$ of whom said that at least one of the pregnancies was unintended. Amongst those who had unintended pregnancies, 15 (3.5\%) opted to have an abortion while the rest prepared to give birth.

\section{Knowledge and accessibility of modern contraceptives among the study participants}

A total of 758 participants (90.3\%) had ever heard about modern contraceptives, $513(67.7 \%)$ had heard about 
Table 1 Background characteristics of study participants

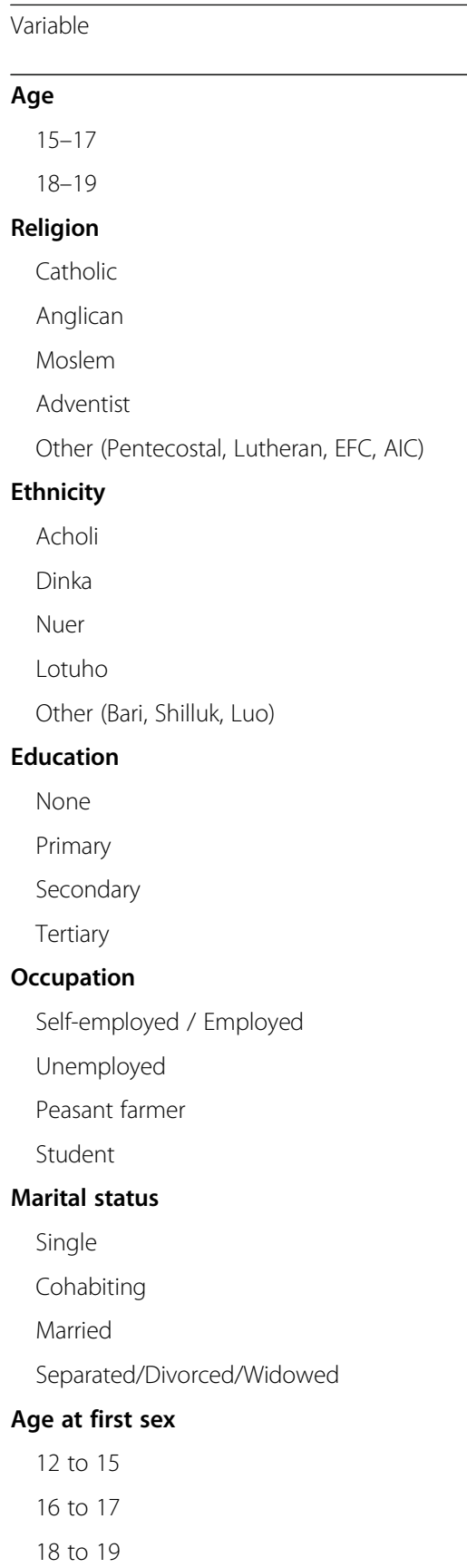

\begin{tabular}{ll}
$\begin{array}{l}\text { Number } \\
(N=839)\end{array}$ & $\begin{array}{l}\text { Percentage } \\
(\%)\end{array}$ \\
\hline 116 & 13.8 \\
723 & 86.2
\end{tabular}

$440 \quad 52.4$

$193 \quad 23.0$

Ever been pregnant

$$
\text { Yes }
$$$$
\text { No }
$$

Number of children alive ( $n-591)$

$$
0
$$$$
1
$$$$
2-4
$$

Partner's age ${ }^{\mathbf{a}}($ Median $=26$, Range $=16$ to 60$)$
Table 1 Background characteristics of study participants (Continued)

\begin{tabular}{lll}
\hline Variable & $\begin{array}{l}\text { Number } \\
(N=839)\end{array}$ & $\begin{array}{l}\text { Percentage } \\
(\%)\end{array}$ \\
\hline 26 to 35 & 331 & 51.3 \\
$36-60$ & 30 & 4.6 \\
$\begin{array}{l}\text { Partner's Education } \\
\text { None }\end{array}$ & 13 & 2.0 \\
Primary & 190 & 29.4 \\
Secondary & 423 & 65.5 \\
Tertiary & 20 & 3.1 \\
Partner's Occupation & & \\
Self-employed / Employed & 193 & 29.9 \\
Unemployed & 267 & 41.3 \\
Peasant farmer & 129 & 20.0 \\
Student & 57 & 8.8 \\
\hline A Afican Inited Church, EFC Evangelical Free Churh
\end{tabular}

AIC African Initiated Church, EFC Evangelical Free Church ${ }^{\text {a Missing data }}$

modern contraceptives from a health worker, 124 (16.4\%) from family and friends, 83 (10.9\%) from school and 38 (5\%) from the media (newspaper, television, radio, drama and posters). A good number of participants $(82.1 \%)$ knew at least two modern contraceptives and the commonly known type was the condom (70.3\%).

Regarding accessibility of the modern contraceptives, almost all the participants (99.6\%) mentioned that the health facility was the only source of modern contraceptives they knew. A total of 589 (70.2\%) of the participants did not know a contraceptive source within 10 min' walk from their homes.

\section{Modern contraceptive use among the study participants}

The prevalence of modern contraceptive use among the 839 participants was $8.7 \%$ (95\% CI: 7.0-10.8). Amongst the users, 31 (42.5\%) were using injectable contraceptives and 40 (59.7\%) had used the contraceptives for 6 months or less. The main reasons for not using modern contraceptives given by 301 (39.3\%) of the non-users was fear of side effects (Table 2).

\section{Prevalence of modern contraceptive use by participants' background characteristics}

According to the participants' background characteristics, participants who had attained up to secondary education had a higher modern contraceptive prevalence (10.1\%) compared to their counterparts. Contraceptive use was slightly more common among those who had lived in the camp for more than 12 months (8.9\%) compared to those who had lived in the camp for a shorter period of time (7.4\%). Participants who had ever been pregnant had almost the same prevalence of modern 
Table 2 Modern contraceptive use among refugee adolescents in Northern Uganda

\begin{tabular}{|c|c|c|c|}
\hline Variable & Number & Percentage & 95\% Confidence Interval \\
\hline \multicolumn{4}{|c|}{ Use of modern contraceptives $(n=839)$} \\
\hline Yes & 73 & 8.7 & 7.0 to 10.8 \\
\hline No & 766 & 91.3 & 89.2 to 93.0 \\
\hline \multicolumn{4}{|c|}{ Method of modern contraceptive used $(n=73)$} \\
\hline Condom & 12 & 16.4 & 9.5 to 27.1 \\
\hline Oral contraceptive (pill) & 4 & 5.5 & 2.0 to 14.0 \\
\hline Injectable contraceptive & 31 & 42.5 & 31.5 to 54.3 \\
\hline Implant & 26 & 35.6 & 25.3 to 47.5 \\
\hline Intra-Uterine Device (IUD) & 0 & 0.0 & \\
\hline \multicolumn{4}{|l|}{ Duration of use $(n=67)$} \\
\hline 6 months or less & 40 & 59.7 & 47.3 to 71.0 \\
\hline 7 to 12 months & 18 & 26.9 & 17.4 to 39.0 \\
\hline More than 12 months & 9 & 13.4 & 7.0 to 24.2 \\
\hline \multicolumn{4}{|l|}{ Reasons for non - use $(n=766)$} \\
\hline Infrequent sex & 83 & 10.8 & 7.6 to 12.4 \\
\hline Cultural / Religious prohibitions & 85 & 11.2 & 9.0 to 13.5 \\
\hline Partner prohibitions & 126 & 16.4 & 14.0 to 19.2 \\
\hline Fear of side effects & 301 & 39.3 & 35.8 to 42.8 \\
\hline Lack of knowledge & 105 & 13.7 & 11.4 to 16.3 \\
\hline Use of traditional methods & 12 & 1.6 & 0.8 to 3.5 \\
\hline Want to become pregnant & 54 & 7.0 & 5.4 to 10.1 \\
\hline
\end{tabular}

contraceptive use (8.8\%) as those who had never been pregnant $(8.4 \%)$. Furthermore, participants whose partners were students had a higher modern contraceptive prevalence rate (19.3\%) compared to those whose partners had other occupations, as shown in Table 3.

Factors associated with modern contraceptive use among the study participants

Using logistic regression, variables which had a p-value less than 0.2 were considered significant at bivariate analysis. They were age $(p=0.153)$, marital status $(p=$ $0.079)$, number of children alive $(p=0.081)$, partner's age $(p=0.007)$, and partner's occupation $(p=0.073)$. In addition, the variables that were plausible according to prior knowledge like education and ever been pregnant were added although their $p$-values were greater than 0.2 . These variables were considered for the multivariate analysis. Statistical significance at multivariate analysis was considered at a p-value of 0.05 . The significant variables at this level were being married $(\mathrm{aOR}=0.11,95 \%$ CI: 0.04 to $0.35, p<0.001$ ) or cohabiting ( $\mathrm{aOR}=0.43$, 95\% CI: 0.20 to $0.93, p=0.032$ ) and having an older partner $(\mathrm{aOR}=0.93,95 \% \mathrm{CI}: 0.86$ to $0.99, p=0.046)$. The significant variables were further assessed for interaction between each other and for confounding with all the other independent variables that were significant at bivariate. However, there was neither interaction nor confounding. Therefore, marital status and partner's age were the only variables associated with modern contraceptive use (Table 4).

\section{Discussion}

This study assessed the prevalence and factors associated with modern contraceptive use among female refugee adolescents in Palabek refugee settlement, Northern Uganda. The prevalence of modern contraceptive use was less than a tenth, and yet almost all (93\%) did not want to become pregnant. Moreover, $70 \%$ of the respondents had ever been pregnant. The contraceptive prevalence rate in our study is much lower than that of the general population of married and unmarried sexually active female adolescents in Uganda, which was reported to be $25.2 \%$ [16]. Several studies from other refugee settings have reported similar findings of low modern contraceptive use among refugee adolescents [15, 22, 23]. For example, in a multi country study of refugee settings, current use of contraceptives was reported to be only $4 \%$ [22]. In addition, a study among refugees in Ghana reported current contraceptive use of $7.3 \%$ [23]. In previous studies, low prevalence of modern contraceptive use in refugee settings was attributed to inadequate knowledge on contraceptives, fear of side effects and partner prohibitions 
Table 3 Prevalence of modern contraceptive use by participants' background characteristics

\begin{tabular}{|c|c|c|c|}
\hline Variable & $\begin{array}{l}\text { Contraceptive use } \\
\text { No. }(\%)\end{array}$ & $\begin{array}{l}\text { Contraceptive Non-use } \\
\text { No. }(\%)\end{array}$ & $\begin{array}{l}95 \% \text { Confidence } \\
\text { Interval }\end{array}$ \\
\hline \multicolumn{4}{|l|}{ Age } \\
\hline 15 to 17 & $10(8.6)$ & $106(91.4)$ & 4.7 to 15.3 \\
\hline 18 to 19 & $63(8.7)$ & $660(91.3)$ & 6.9 to 11.0 \\
\hline \multicolumn{4}{|l|}{ Religion } \\
\hline Catholic & $38(8.6)$ & $402(91.4)$ & 6.3 to 11.7 \\
\hline Anglican & $15(7.8)$ & $178(92.2)$ & 4.7 to 12.5 \\
\hline Adventist & $6(9.1)$ & $60(90.9)$ & 4.1 to 18.9 \\
\hline Other (Pentecostal, Lutheran, EFC, AIC) & $13(8.0)$ & $108(90.0)$ & 6.0 to 16.2 \\
\hline \multicolumn{4}{|l|}{ Ethnicity } \\
\hline Acholi & $65(9.9)$ & $594(90.1)$ & 7.8 to 12.4 \\
\hline Dinka & $1(5.6)$ & $17(94.4)$ & 0.7 to 32.0 \\
\hline Nuer & $1(5.3)$ & $18(94.7)$ & 0.7 to 30.6 \\
\hline Lotuho & $3(6.5)$ & $43(93.5)$ & 2.1 to 18.6 \\
\hline Other (Bari, Shulluk, Luo) & $3(3.1)$ & $94(96.9)$ & 1.0 to 9.2 \\
\hline \multicolumn{4}{|l|}{ Education } \\
\hline None & $4(4.9)$ & $77(95.1)$ & 1.9 to 12.5 \\
\hline Primary & $53(8.9)$ & $542(91.1)$ & 6.9 to 11.5 \\
\hline Secondary & $15(10.1)$ & $133(89.9)$ & 6.2 to 16.2 \\
\hline Tertiary & $1(6.7)$ & $14(93.3)$ & 0.9 to 36.9 \\
\hline \multicolumn{4}{|l|}{ Occupation } \\
\hline Self-employed/Employed & $3(9.1)$ & $30(90.9)$ & 2.9 to 25.1 \\
\hline Unemployed & $29(8.7)$ & $306(91.3)$ & 6.1 to 12.2 \\
\hline Peasant farmer & $23(7.5)$ & $282(92.5)$ & 5.1 to 11.1 \\
\hline Student & $18(10.8)$ & $148(89.2)$ & 6.1 to 16.6 \\
\hline \multicolumn{4}{|l|}{ Marital status } \\
\hline Single & $19(8.2)$ & $214(91.8)$ & 5.3 to 12.4 \\
\hline Cohabiting & $42(11.0)$ & $339(88.0)$ & 8.2 to 14.6 \\
\hline Married & $6(3.7)$ & $157(96.3)$ & 1.7 to 8.0 \\
\hline Separated/Divorced/Widowed & $6(9.7)$ & $56(90.3)$ & 4.4 to 20.0 \\
\hline \multicolumn{4}{|l|}{ Age at first sex } \\
\hline 12 to 15 & $13(7.7)$ & $156(92.3)$ & 4.5 to 12.8 \\
\hline 16 to 17 & $52(9.7)$ & $485(90.3)$ & 7.4 to 12.5 \\
\hline 18 to 19 & $8(6.0)$ & $125(94.0)$ & 3.0 to 11.6 \\
\hline \multicolumn{4}{|l|}{ Number of children alive } \\
\hline 0 & $1(3.2)$ & $30(96.8)$ & 0.4 to 20.2 \\
\hline 1 & $33(12.0)$ & $242(88.0)$ & 8.6 to 16.4 \\
\hline 2 & $17(7.2)$ & $219(92.8)$ & 4.5 to 11.3 \\
\hline $3-4$ & $1(2.0)$ & $48(98.0)$ & 0.2 to 13.4 \\
\hline \multicolumn{4}{|l|}{ Partner's Education } \\
\hline None & $1(7.7)$ & $12(92.3)$ & 1.0 to 41.2 \\
\hline Primary & $17(8.9)$ & $173(91.1)$ & 5.6 to 13.9 \\
\hline Secondary & 45 (10.6) & $378(89.4)$ & 8.0 to 14.0 \\
\hline Tertiary & $1(5.0)$ & $19(95.0)$ & 0.6 to 29.4 \\
\hline
\end{tabular}


Table 3 Prevalence of modern contraceptive use by participants' background characteristics (Continued)

\begin{tabular}{llll}
\hline Variable & $\begin{array}{l}\text { Contraceptive use } \\
\text { No. (\%) }\end{array}$ & $\begin{array}{l}\text { Contraceptive Non-use } \\
\text { No. (\%) }\end{array}$ & $\begin{array}{l}\text { 95\% Confidence } \\
\text { Interval }\end{array}$ \\
\hline $\begin{array}{l}\text { Partner's Occupation } \\
\text { Self-employed/Employed }\end{array}$ & $22(11.4)$ & $171(88.6)$ & 7.6 to 16.7 \\
Unemployed & $24(9.0)$ & $243(91.0)$ & 6.1 to 13.1 \\
Peasant farmer & $7(5.4)$ & $122(94.6)$ & 2.6 to 11.0 \\
Student & $11(19.3)$ & $46(80.7)$ & 11.0 to 31.7 \\
\hline
\end{tabular}

$[18,22,24]$. However, in our study knowledge of contraceptives was high and can therefore not explain the low prevalence of contraceptive use among adolescents in Palabek refugee settlement. The main reason for non-use was fear of side effects. The low prevalence could also be attributed to poor access to modern contraceptives since $70.2 \%$ of the participants could not access a contraceptive source within 10 min' walk from their homes.

Over two thirds of the participants had ever been pregnant. This proportion is considerably higher than that in the general population of adolescents aged 1519 years $(28.8 \%)$ and $18-19$ years $(46.8 \%)$ in Uganda who have begun child bearing [16]. These findings highlight an urgent need for improved access to modern contraceptives in this population and setting.

The factors significantly associated with modern contraceptive use among the participants were marital status and partner's age. Participants who were married and those who were cohabiting were 89 and $57 \%$ less likely to use modern contraceptives respectively than their counterparts who were single. In contrast, previous studies among nonrefugees adolescents have shown that adolescents who were married were more likely to use modern contraceptives compared to those who were single $[25,26]$. This inconsistency could have been brought about by the difference in setting and study population of the studies compared to ours. The association between modern contraceptive use and marital status observed in our study can be explained by the possibility that married adolescents could have been prohibited by their partners from using modern contraceptives. Partner prohibition emerged as the second commonest reason for contraceptive non-use in this study. This could explain why the adolescents who were married or cohabiting were less likely to use contraceptives than those who were single. Adolescents who were single had no regular partners to prohibit them from using modern contraceptives. Another possible explanation for this association is that adolescents who are married or cohabiting are more likely to desire to have children than those who are single. This is because many of them are expected by society to

Table 4 Factors associated with modern contraceptive use among refugee adolescents

\begin{tabular}{|c|c|c|c|c|}
\hline Variable & $\begin{array}{l}\text { Crude OR } \\
(95 \% \mathrm{Cl}) \\
\end{array}$ & $P$-Value & Adjusted OR (95\% Cl) & $P$-Value \\
\hline \multicolumn{5}{|l|}{ Age in years } \\
\hline Median (IQR): 19 (18-19) & 0.83 (0.64 to 1.07$)$ & 0.153 & 0.75 (0.48 to 1.16$)$ & 0.194 \\
\hline \multicolumn{5}{|l|}{ Marital status } \\
\hline Single & 1.00 & & 1.00 & \\
\hline Cohabiting & 1.40 (0.79 to 2.46$)$ & 0.250 & 0.43 (0.20 to 0.93$)$ & 0.032 \\
\hline Married & 0.43 (0.17 to 1.10$)$ & 0.079 & 0.11 (0.04 to 0.35$)$ & $<0.001$ \\
\hline Separated/Divorced/Widowed & 1.21 (0.46 to 3.16$)$ & 0.702 & 0.29 (0.08 to 1.00$)$ & 0.050 \\
\hline \multicolumn{5}{|l|}{ Number of children alive } \\
\hline Mean (SD): 1.5 (0.727) & 0.70 (0.46 to 1.05$)$ & 0.081 & 0.83 (0.51 to 1.33$)$ & 0.431 \\
\hline \multicolumn{5}{|l|}{ Partner's age } \\
\hline Median (IQR): 26 (24-30) & $0.91(0.86-0.98)$ & 0.007 & 0.93 (0.86 to 0.99 ) & 0.046 \\
\hline \multicolumn{5}{|l|}{ Partner's Occupation } \\
\hline Self-employed/Employed & 1.00 & & & \\
\hline Unemployed & 0.77 (0.42 to 1.41$)$ & 0.396 & $0.82(0.43$ to 1.58$)$ & 0.553 \\
\hline Peasant farmer & 0.45 (0.18 to 1.08$)$ & 0.073 & 0.49 (0.20 to 1.24$)$ & 0.134 \\
\hline Student & $1.86(0.84$ to 4.11$)$ & 0.126 & & 0.152 \\
\hline
\end{tabular}


conceive after marriage [27]. Because of this, married adolescents or those who are cohabiting are less likely to opt for modern contraceptives.

The other factor that was significantly associated with modern contraceptive use was the partner's age. Our results showed that modern contraceptive use decreased by $7 \%$ with every unit increase in the partner's age. That is, adolescents with older partners were less likely to use modern contraceptives than those with partners their age. In contrast, a previous study among married women aged 15 to 49 years in Nigeria showed no association between partner's age and modern contraceptive use [28]. This discrepancy could be explained by differences in age inclusion and supports our postulation that adolescents have lower negotiating power compared with adult women, especially surrounding matters concerning their sexual and reproductive health. This is as explained by the gender and power theory [29]. The fact that gender and power imbalances deepen with increasing age disparities within couples has been confirmed in previous studies [30, 31].

Some of the strengths of this study are: standardised approaches like pre-testing of questionnaires, translation and back translation of questionnaires to ensure that meaning is not altered, were used to carry out this study. This helped to minimise misclassification bias, and increases the ability to repeat and replicate the findings. Furthermore, a large sample size was used and this gave the study a high power enough to answer its research questions.

However, this study has some limitations. First, the sample was not representative because a non-random sampling technique (consecutive sampling) was used. However, this was minimised by collecting the sample from all sections of the refugee settlement. Secondly, this study used questionnaires to obtain sensitive information on sexual and reproductive history of the participants. These questions are subject to social desirability bias where participants are likely to give responses that are socially acceptable instead of the true responses. This bias was minimised by conducting interviews in calm and friendly environments. Finally, this was a cross-sectional study so causal relationships could not be established.

\section{Conclusion}

In conclusion, less than a tenth of the participants were using modern contraceptives, and this leaves them vulnerable to adolescent pregnancies and their associated complications. The most at risk groups were adolescents who were either married or cohabiting and those with much older partners. The main reasons for not using modern contraceptives were fear of side effects, partner prohibition and lack of knowledge.
Our study shows that there is an urgent need for measures to improve adolescents' access to high-quality sexual and reproductive healthcare in refugee settings. Future interventions should empower adolescents in refugee settings to make decisions about their own health including initiating a contraceptive method, address their fear of side effects and knowledge gaps, and ensure better contraceptive counselling techniques so as to improve use of modern contraceptives.

\section{Abbreviations \\ IUDs: Intra-uterine devices; EFC: Evangelical Free Church; AIC: African Initiated Church; Cl: Confidence Interval; OR: Odds Ratio; SD: Standard Deviation \\ Acknowledgements \\ We would like to acknowledge all the refugee adolescents who accepted to participate in this study, the research assistants Anthony Okello, Richard Kidega, Acayo Stella, Charles Ochan and Suzan Achayo, and the staff of the department of Obstetrics and Gynaecology, Makerere University for all the guidance and support rendered. We also acknowledge the funders of this study, Swedish International Development Agency (Sida) and Makerere University through the project number Sida 344.}

\section{Authors' contributions}

RB conceptualised and designed the study, planned and carried out the analysis, interpreted results and wrote the manuscript. She is the gurantor and responsible investigator of the study. AC, EL, KGD, RC and JBK planned and supervised the study, contributed in analysis, interpreted results, and contributed in the writing and reviewing of the manuscript. JKT and GN planned the study and reviewed the manuscript. All authors read and approved the final manuscript.

\section{Funding}

This study was funded in part by the Swedish International Development Cooperation Agency (Sida) and Makerere University under Sida contribution No: 51180060

\section{Availability of data and materials}

The datasets used and/or analysed during the current study are available from the corresponding author on reasonable request.

\section{Ethics approval and consent to participate}

Ethical approval was obtained from the Makerere University School of Medicine Higher Degrees Research Ethics Committee (REC REF 2018-059), and from Uganda National Council of Science and Technology (SS 4876). Administrative clearance was also obtained from the Office of the Prime Minister, Department of Refugees, for permission to carry out research among refugees. Written informed consent was obtained for participants who were 18 years and above, and assent for those below 18 years before being included in the study. Confidentiality was maintained by the use of number codes instead of participant names. Furthermore, interviews were conducted in a private area where the conversations could not be over heard.

\section{Consent for publication}

Not applicable.

\section{Competing interests}

The authors declare that they have no competing interests.

\section{Author details}

${ }^{1}$ Department of Obstetrics and Gynaecology, School of Medicine, College of Health Sciences, Makerere University, Kampala, Uganda. ${ }^{2}$ Department of Women's and Children's Health, Division of Obstetrics and Gynaecology, Karolinska Institutet, and Karolinska University Hospital, Stockholm, Sweden. ${ }^{3}$ Department of Women's and Children's Health, Uppsala University, Uppsala, Sweden. ${ }^{4}$ Department of Paediatrics and Child health, School of Medicine, College of Health Sciences, Makerere University, Kampala, Uganda. ${ }^{5}$ Department of Nursing, School of Health Sciences, College of Health Sciences, Makerere University, Kampala, Uganda. 
Received: 20 February 2020 Accepted: 11 May 2020

Published online: 20 May 2020

\section{References}

1. UNHCR. Figures at a glance; 2019 .

2. World Bank. Uganda: supporting refugees and host communities to become secure and self-reliant; 2019.

3. UNICEF. Uganda humanitarian situation report - January to June 2019; 2019.

4. UNHCR. Comprehensive refugee response framework Uganda, the way forward; 2017

5. WRC. Facts and figures; 2020

6. Profamilia. Encuestas: Fecundidad y Salud general; 2000. p. 48.

7. Ganchimeg T, Ota E, Morisaki N, Laopaiboon M, Lumbiganon P, Zhang J, et al. Pregnancy and childbirth outcomes among adolescent mothers: a World Health Organization multicountry study. BJOG. 2014; 121(Suppl 1):40-8.

8. Chen XK, Wen SW, Fleming N, Demissie K, Rhoads GG, Walker M. Teenage pregnancy and adverse birth outcomes: a large population based retrospective cohort study. Int J Epidemiol. 2007:36(2):368-73.

9. Sedgh $\mathrm{S}$, Singh $\mathrm{S}$, Hussein R. Intended and unintended pregnancies worldwide in 2012 and recent trends. Stud Fam Plan. 2014:45(3):301-14.

10. WFd A, Diniz MB, ESVBd F, LMRd A, Evangelista CB. Complications in adolescent pregnancy: systematic review of the literature. Einstein (São Paulo). 2015;13:618-26.

11. WHO. Adolescent pregnancy; 2018.

12. $\mathrm{MoH}$. Adolescent health policy guidelines and service standards; 2012.

13. MoH. The National Policy Guidelines and Service Standards for Sexual and Reproductive Health and Rights. Uganda. 2006. p.19-20. https://stage.prb. org/wp-content/uploads/2018/05/National-Policy-Guidelines-and-ServiceStandards-for-Sexual-and-Reproductive-Health-and-Rights-2006.Uganda.pdf.

14. Kabagenyi A, Habaasa G, Rutaremwa G. Low contraceptive use among young females in Uganda: does birth history and age at birth have an influence? Analysis of 2011 demographic and health survey. J Contraceptive Stud. 2016;1(1):4

15. UNHCR. Baseline study: documenting knowledge, attitudes and practices of refugees and the status of family planning services in UNHCR's operations in Nakivale refugee settlement, Uganda; 2011.

16. UDHS. Demographic and health survey 2016, key indicators report; 2016.

17. Blanc A, Tsui A, Croft T, Trevitt J. Patterns and trends in adolescents contraceptive use and discontinuation in developing countries and comparisons with adult women. Int Perspect Sex Reprod Health. 2009:2:63-71.

18. Okanlawon K, Reeves M, OF A. Contraceptive use: knowledge, perceptions and attitudes of refugee youths in Oru refugee camp, Nigeria. Afr J Reprod Health. 2010;14(4):16-25.

19. UNHCR. Uganda refugee response monitoring settlement fact sheet: Palabek / January 2018; 2018

20. Kish L. Survey sampling. New York: Wiley; 1965. p. 78-94.

21. Hulley S. Designing clinical research. 4th ed; 2013.

22. Tanabe M, Myers A, Bhandari P, Cornier N, Doraiswamy S, Krause S. Family planning in refugee settings: findings and actions from a multi-country study. Confl Heal. 2017;11(1):9.

23. Ganle JK, Amoako D, Baatiema L, Ibrahim M. Risky sexual behaviour and contraceptive use in contexts of displacement: insights from a crosssectional survey of female adolescent refugees in Ghana. Int J Equity Health. 2019;18(1):127.

24. Ochako R, Mbondo M, Aloo S, Kaimenyi S, Thompson R, Temmerman M, et al. Barriers to modern contraceptive methods uptake among young women in Kenya: a qualitative study. BMC Public Health. 2015:15(1):118.

25. Nyarko SH. Prevalence and correlates of contraceptive use among female adolescents in Ghana. BMC Womens Health. 2015;15(1):60.

26. de Vargas Nunes Coll C, Ewerling F, Hellwig F, de AJD B. Contraception in adolescence: the influence of parity and marital status on contraceptive use in 73 low-and middle-income countries. Reprod Health. 2019;16(1):21.

27. UNICEF. Child marriage, adolescent pregnancy and school dropout in South Asia; 2019.

28. Ibisomi L. Is age difference between partners associated with contraceptive use among married couples in Nigeria? Int Perspect Sex Reprod Health. 2014:40(1):39-45.
29. Wingood GM, DiClemente RJ. Application of the theory of gender and power to examine HIV-related exposures, risk factors, and effective interventions for women. Health Educ Behav. 2000;27(5):539-65.

30. Bauermeister JA, Zimmerman M, Xue Y, Gee GC, Caldwell CH. Working, sex partner age differences, and sexual behavior among African American youth. Arch Sex Behav. 2009;38(5):802-13.

31. Madiba S, Ngwenya N. Cultural practices, gender inequality and inconsistent condom use increase vulnerability to HIV infection: narratives from married and cohabiting women in rural communities in Mpumalanga province, South Africa. Glob Health Action. 2017;10(sup2):1341597.

\section{Publisher's Note}

Springer Nature remains neutral with regard to jurisdictional claims in published maps and institutional affiliations.
Ready to submit your research? Choose BMC and benefit from:

- fast, convenient online submission

- thorough peer review by experienced researchers in your field

- rapid publication on acceptance

- support for research data, including large and complex data types

- gold Open Access which fosters wider collaboration and increased citations

- maximum visibility for your research: over $100 \mathrm{M}$ website views per year

At $\mathrm{BMC}$, research is always in progress.

Learn more biomedcentral.com/submissions 